\title{
Papers
}

\section{Right of lights ahead!}

Received (in revised form): 3rd June, 2008

\section{Andrew Francis}

Andrew Francis is barrister and member of Chambers at Serle Court. His practice specialises in Rights of Light and restrictive covenants affecting freehold land. He is the co-author of Rights of Light, The Modern Law (2nd edn., 2007 - Jordans) and is the author of Restrictive Covenants and Freehold Land - a Practitioner's Guide (2nd edn., 2005, Jordans). He has appeared as counsel in the two most important recent cases on rights of light in the last two years in the Court of Appeal, Regan vs Paul Properties, and RHJ Ltd vs FT Patten (Holdings) Ltd.

Correspondence: Andrew Francis, Serle Court, Lincoln’s Inn, London WC2A 3QS, UK; Tel: +44 (0)20 7242 6105; E-mail: afrancis@ serlecourt.co.uk

\begin{abstract}
Rights of light are a complex subject in English Law. Developers ignore this area of law at their peril. Failure to take rights of light into account can at best result in the expense of redesigning buildings and at worst, orders of the Court ordering work to stop or work done to be pulled down. There are steps that can be taken at the first stages of development that will identify whether rights of light issues exist and what can be done about them. Planning rules do not govern rights of light so pre-planning advice on these rights is crucial. This paper sets out the law in brief and then concentrates on the questions to ask and the practical steps to take, in conjunction with expert surveyors and lawyers. Journal of Building Appraisal (2008) 4, 5-13. doi:10.1057/jba.2008.18
\end{abstract}

\section{Keywords:}

rights of light, lumen, planning, injunction, damages, costs

\section{INTRODUCTION}

This is not a paper about the detail of the law of rights of light in England and Wales. Those seeking such detail should consult either the law books or the experts on this topic.

This paper is about the practical side of rights of light.

\section{A LITTLE LAW TO START WITH}

A little law has to be explained at the beginning of this paper in order that the rest of it can be understood by non-lawyers.

A right of light, if established, is an easement. This is a legal interest in land that confers a right on one party to do things over the land of the other party, short of actual possession. Rights of way, rights to receive or drain water and, in this context, rights of light, are just some examples of easements. Rights of light can only be acquired for the benefit of buildings. ${ }^{1}$ The owner of a building will have acquired a right of light by one of three means applicable to easements. These are, first, by an express agreement, known as an express grant. Secondly, by an implied grant. This may arise under a number of different circumstances, particularly where there are sales off by a common vendor, or lessor. The main way of acquiring a right of light under this second heading is under section 62 of the Law of Property Act 1925, or alternatively, under what is known as the 
principle of non-derogation from grant. Thirdly, and most importantly in rights of light, an easement of light may be acquired by prescription. This is a form of long enjoyment under either section 3 of the Prescription Act 1832, or under a legal fiction known as Lost Modern Grant. The principal period for the enjoyment of light is 20 years. Significantly, and unlike other easements, a right of light may be acquired by a tenant of a building under the 1832 Act, not only against third parties, but also against his own landlord, subject to the terms of the lease. All these matters are of course very much within the expertise of solicitors, counsel or rights of light experts and, as stated above, the details in precise terms of how a right of light may be acquired or lost is within the province of these experts.

\section{WHAT IS IMPORTANT - WILL RIGHTS OF LIGHT BE IN ISSUE?}

What does matter for the purposes of this paper, and what is important generally, is that developers and those advising them, such as project managers, architects and surveyors, should have a system for checking whether a building or redevelopment project is going to be affected by rights of light issues. Clearly, there are always two sides to rights of light disputes. On the one side, the developer will want to ensure that his development is not going to be hindered by claims to light from adjoining building owners or occupiers. On the other side, there are adjoining owners or occupiers who will want to ensure that their rights of light are not the subject of interference to an actionable extent. Both sides will need to know what their rights are. So what this paper seeks to do is to provide a framework for those who are engaged in building work and redevelopment of land in seeking to ensure that rights of light are dealt with in an effective and timely manner. In addition to those who may be affected by interference with rights of light, this paper may serve to give them some assistance in dealing with rights of light issues as against the developer.

\section{SOME BASIC RULES}

Without these basic rules it is of course impossible to understand the principles that are set out below. As stated above, the fine details are not for this paper.

(i) A right of light is an easement and that is a legal interest in land. As stated above, it may be acquired in at least three principal ways.

(ii) Interference with an easement of light may result in an injunction. This is an Order of the Court that may prevent further work of development being carried out or may, in some cases, order work which has been put up to be pulled down. Disobedience to such an Order can result in the imprisonment for contempt of those who have ignored or broken the Order. The leading case on this is the right of light case in Central Brighton heard in 2006, Regan vs Paul Properties \& Others. ${ }^{2}$ In that case, the Court of Appeal re-emphasised the principle that where a right of light (if not other property interests) is the subject of an actionable interference, the prima facie remedy will be an injunction. Exceptional circumstances will have to be proved by the defendant/developer to escape that consequence. Therefore, developers are now firmly on notice if they build without taking into account the other party's property interests, such as rights of light. They will probably face an Order of the Court asking them to stop work, to cut back their building and, if necessary, to pull down that part of the building that actionably interferes with the light and other rights enjoyed by the adjoining owner.

(iii) Measurement of light for rights of light purposes is carried out scientifically. It has nothing to do with light meters. Rights of light surveyors will produce special 
diagrams and tables to show the 'before and after' effect of the development. These studies are critical when assessing whether or not rights of light are going to be actionably interfered with. While the leading authority, Colls vs Home \& Colonial Stores, decided by the House of Lords in $1904,{ }^{3}$ provides a flexible test on what may or may not be an actionable interference, and proceeds on the assumption that you are not entitled to every bit of light coming into your building, there is also a well-developed scientific basis for measuring light. It is important to understand that without at least a desktop or outline study prepared by a competent rights of light surveyor, it is impossible to assess the extent to which any interference is likely to be actionable.

(iv) The standard of light in England and Wales is based on the theory that the minimum amount of light to which a person is entitled, measured at desk height ( $850 \mathrm{~mm}$ above the floor), is 1 Lumen. In scientific terms this is 0.2 per cent of the whole hemisphere of sky that could theoretically illuminate the room or rooms in the building in question. This is not a particularly high standard. It is based on the total amount of illumination from the whole sky at the winter equinox on a cloudy-bright day at noon in the latitude of England and Wales. From this a general guideline has emerged to the effect that is a room if already well lit to the standard of 0.2 per cent (or 1 lumen) to at least 50 per cent of its area, and if that standard of illumination is reduced by the proposed development to less than 50 per cent of that area, that is prima facie an actionable interference. Further principles have been developed for badly lit rooms. If a room is already badly lit (ie less than 50 per cent of its area is illuminated to the 0.2 per cent or 1 lumen standard before the building work takes place) then every little bit of light remaining is precious. So in very round terms, a reduction of 10 per cent or more of the available light in that room will be regarded as actionable.

(v) The technical details of the law are complex and, as stated above, advice as to the manner of acquisition, or loss of an easement, or its measurement should be left to experts - whether they be solicitors, counsel or surveyors.

(vi) The rules that apply in planning law are not the same as those that apply in the civil law described above. In planning law, Building Research Establishment (BRE) standards for daylight and sunlight apply. There are consequently two sets of different tests that may determine whether, on the one hand, planning law and its requirements are satisfied, and on the other hand, whether or not the requirements of the civil law are satisfied. This paper looks at rights of light from purely the civil law angle. It cannot be over-stressed that surveyors and others who approach a matter purely from the planning angle will often be advising their clients quite inappropriately and negligently if they fail to take into account civil law standards of light and its measurement where such rights of light exist.

(vii) The fact that the developer has obtained planning consent does not mean that his proposed building conforms to the civil law. Therefore, it is vitally important that tests be carried out pre planning to ascertain whether or not the civil law standard based on the 1 lumen or 0.2 per cent of the sky standard has been satisfied. As pointed out above, if the developer infringes the standard to an actionable extent, he will face an injunction claim in the civil court, that is, the High Court or the County Court and, therefore, may face a stoppage in the work, or an order that the building be pulled down so far as it interferes actionably with the adjoining owner's light.

(viii) Two recent cases have raised the stakes in rights of light matters and require developers now to be much more aware at the early stages of development so far as they 
may be rights of light risks. The two cases are first, the case referred to above, Regan vs Paul Properties \& Others in $2006^{4}$ and, on the question of damages for loss of light, Tamares (Vincent Square) Ltd vs Fairpoint Properties (Vincent Square) $L t d{ }^{5}$ The latter case reinforces the general principle that when assessing damages for interference with light, in lieu of an injunction, damages may not be based purely on the loss to the claimant (to which special rules apply in rights of light cases) but rather on the appropriate percentage of the net development value, or net profit that the developer is making in respect of that part of the building that interferes actionably with the adjoining owner's light. In Tamares, the court stressed that the percentage should be 'fair'. While there is a huge range in the cases as to what percentage is a fair one, ranging between 5 per cent and as high as 50 per cent or even higher, any developer wishing to set aside a sum as a contingency for damages must, therefore, be prepared to have an expert assessment made of the net profit of the infringing part of the development. It should also be stressed, from the point of view of surveyors, that the basic principle often adopted by surveyors known as the 'Stokes Percentage' based on Stokes vs Cambridge Corporation in $1961^{6}$ (being one-third of the net development value or uplift or net profit) does not apply in all cases. Many factors will go to dictate what is the appropriate percentage and, therefore slavish adherence to the 'Stokes Percentage' is wrong and often negligent. Recent authority emphasised in Tamares makes it clear that all relevant and varied factors have to be taken into account in assessing what is appropriate as damages when they are awarded in lieu of an injunction. At the end of the day, as was said in one of the cases on this subject (Amec Developments Ltd vs Jurys Hotel Management (UK) Ltd), ${ }^{7}$ 'the deal has to feel right' in terms of the amount to be awarded. The same principles, of course, apply when considering release fees in negotiated settlements of rights of light claims. However, it must also be stressed at this stage that, bearing in mind what the Court of Appeal said in Regan, developers must always proceed on the footing that if they are to avoid the risk of infringement and an injunction with all the costs of the delays, etc that such a risk will entail, it is better to try and buy off the adverse rights by negotiation.

(ix) Finally, in civil law cases, if litigation is unavoidable the costs of that litigation (such costs being the Court costs, the lawyers' costs, the witnesses' costs and the experts' costs) will generally follow the event, so that the losing party will usually have to pay the winning party's costs. In litigation of any substance this can amount to at least $£ 100,000$ per side. Each party, therefore, has to factor in the risk of losing and having to pay the other side's costs. As stated above, this is not an paper on the detailed law, nor is it an paper on the detailed law of costs. If further advice is needed, lawyers should be consulted on how costs risks should be assessed and how they can be minimised.

\section{PRACTICAL MATTERS - FIRST STAGE}

The real focus in this paper is on the practical and prudent steps that a developer or a potential objector can take when a development is proposed that may raise rights of light issues. From the point of view of the developer, he will be considering his development at a very early stage - often at the pre-acquisition and pre-funding stages. From the point of view of a potential objector as an adjoining owner, the first time that that person will be aware of the proposal will probably be at the planning notification stage. In practical 
terms, rights of light will usually be of major concern to developers in city centres and built-up areas. But they can also arise in rural areas where developments may be near existing buildings of some age. One other matter of concern may be restrictive covenants, or other interests affecting the user of land that may prevent or limit the development of land. This paper will not deal with that large and complex subject. Covenants, however, can never be ignored. One of the features of rights of light in particular is that while the lawyers will generally be commissioned to do what is called 'due diligence' on the title, rights of light being based invariably on prescription (long enjoyment for at least 20 years) will not usually appear on the title. Therefore, as suggested below, some practical steps have to be taken to see whether or not long enjoyment of light is a real risk in any particular case. Other matters that may affect title, such as covenants, should, of course, always be on the register of the title land that is affected by those covenants, and lawyers will be concerned to examine whether those covenants are enforceable. In this context, and in some other cases, there are agreements, or covenants that limit the extent to which buildings can be erected in order to avoid interference with light. These are often troublesome as a matter of interpretation. They may be construed as either restrictive agreements, or agreements which simply give liberty, or permission to build. Once again, this is a complex area of law, and where agreements are encountered on titles that may affect the ability of the developer to build in the context of rights of light, expert legal opinion must be taken.

\section{PRACTICAL MATTERS - SECOND STAGE}

The practical steps suggested by the author are as follows:

(i) Take advice on rights of light issues at the pre-planning stage. This is absolutely crucial. There is no point getting an expensively procured planning consent if the proposed building has to be subsequently altered, with the consequential delay on either seeking revised, or fresh consent that may, or may not be available. It is, therefore, essential that the developer uses expert rights of light surveyors to work with the architects and the other persons concerned with the project at the earliest possible stage. This may even have to be done before acquisition, or before funding to see what the maximum envelope for development could be without actionable interference with adjoining owners' light.

(ii) Go and look at the site. Take stock of surrounding buildings. The age of buildings and apertures is crucial in rights of light. Generally, as stated above, rights of light must be continuously enjoyed for 20 years, and that period is usually measured back from the present day. Site inspections are therefore vital. No one should accept instructions in any job where rights of light might be an issue without having a site inspection, either by themselves, or by a suitably qualified expert. If one is on a site inspection the following features should be looked at:

- Age of surrounding buildings generally.

- Age of your building and apertures if you want to assert rights of light.

- Signs of alterations in apertures. This may be in either the horizontal or the vertical plane. This is known often as the principle of 'coincidence' in rights of light, the details of which can be complex and is a subject for the experts. If there is coincidence there may be a possibility of claiming a right of light through the old aperture, even if the present aperture in its coincident place has not been there for a full period of 20 years. This is where one has to look at mortar joints and other features surrounding apertures that may indicate signs of movement. 
- Signs of non-enjoyment. Internal boarding-up, for example in security warehouses and security stores. Sometimes you see this on the first and second floors of department stores where show cards and other hoardings are permanently inside the apertures.

- Signs of abandonment. These are often easy to detect but hard to advise on because of the different ways in which abandonment can be achieved. The classic case is the fully bonded-in set of brickwork with the removal of all the features of the original aperture. There are, however, many 'halfway houses' that show, as in the image below, different ways of blocking up windows that may, or may not be permanent. The key to asserting abandonment successfully is to show that the bricking-up, etc of the window that showed an intention never to assert the easement of light through that aperture again. Abandonment can be difficult to prove. It should also be distinguished firmly from non-enjoyment referred to above where the person actually claiming the light has by his own act stopped his enjoyment. Figure 1 shows various apertures where different methods to block them up have been used. Some are more permanent than others so the question of abandonment (or non-enjoyment) can arise from a simple visual inspection.

- 'Ancient lights' signs, or other signs and stone plaques. These generally only amount to an assertion of a claim to light, with no legal effect as such. They may, however, in some cases, be important in historical terms and are, of course, a warning to the possible assertion of light, and if dates, etc are on the stone plaques they may establish the age of certain features (Figure 2).

(iii) Take legal advice on the title. This is particularly important not only as regards the registered title that will be kept by the Land Registry, but also to ensure that light obstruction notices are not registered at the local Land Charges Register. Light obstruction notices registered under the Rights of Light Act 1959 have a particular importance, and if they are not objected to by the issue of a Claim Form within a year of their registration, that will be fatal to the assertion of a right of light under the 1832 Act. In the City of London, where the Custom of London prevents

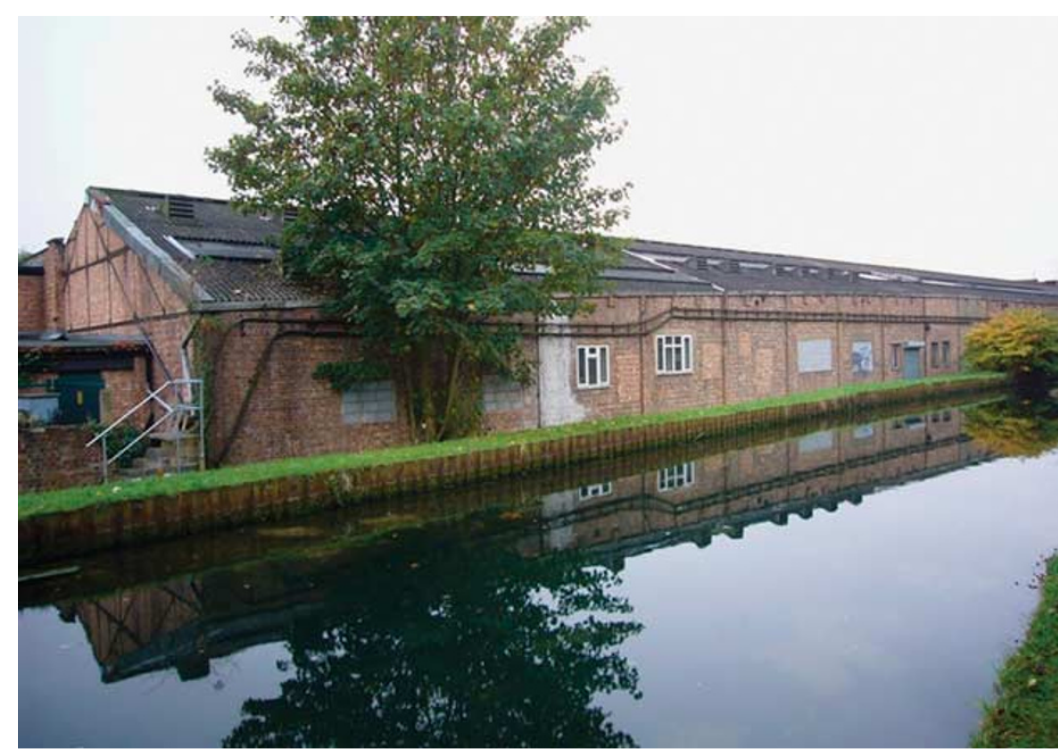

Figure I: Examples where various apertures have been blocked with different methods 


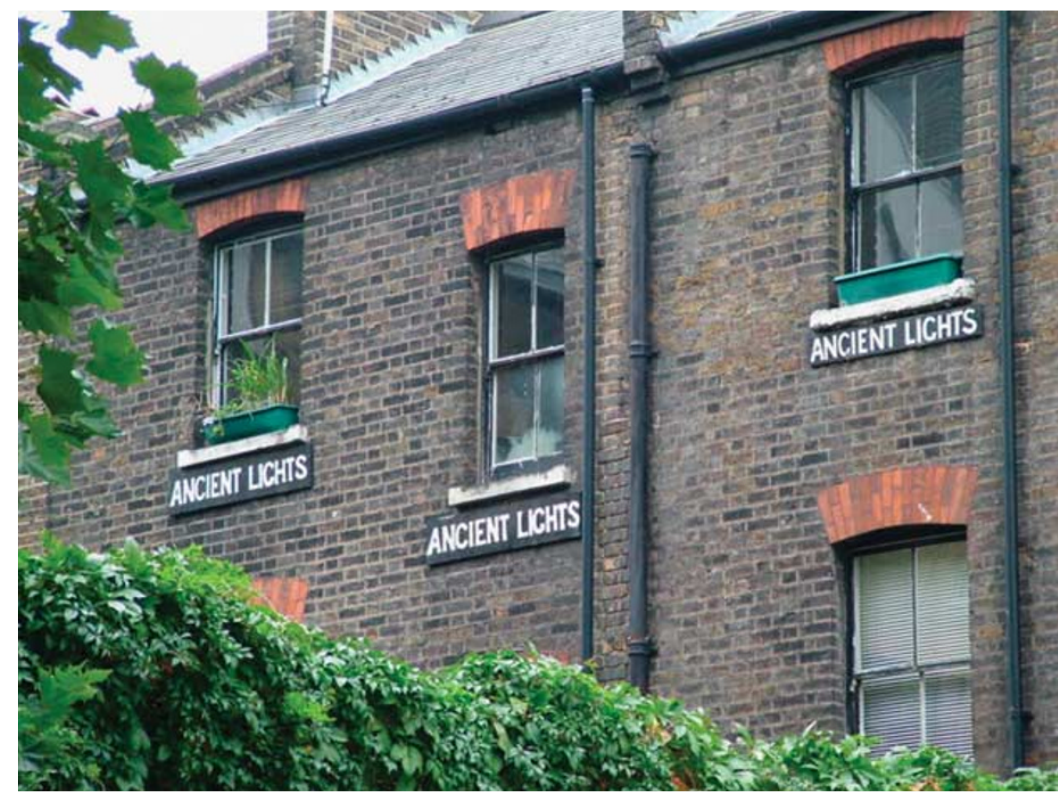

Figure 2: Examples of 'ancient lights' signs

assertion of the alternative claim based on the fiction of Lost Modern Grant, this can be particularly fatal. Such an event occurred in the case between Bowring and Scottish Widows in $1995 .^{8}$

(iv) Commission the experts. At this stage of the process you should be able to build up a picture of whether rights of light are likely to exist over and against your development site as a matter of evidence. If so, the expert right of light surveyor, who should by now have been instructed, will be able to input the site survey data into his computer so as to create the model from which he can produce the diagrams and tables that will show the extent of interference to light by the proposed building and whether or not it is actionable. All suitably qualified rights of light surveyors have modern computer programs using CAD-type technology that will enable them to produce diagrams and three-dimensional models based on the proposed building, as well as the existing site, in order to see whether or not light will be interfered with, and it will also enable cut-backs to be designed in order to remove actionable interference.

(v) Avoid guesswork. Measurements of the site and the proposed buildings, etc are vital. As stated above, a site visit is particularly crucial. Never use back of the envelope drawings or ideas that can ultimately prove to be wrong when proper site surveys are carried out and when desktop or more detailed models are created of the likely effect of rights of light. Finally, do not rely on planning data for Building Research Establishment tests for daylight and sunlight, as these will not be conclusive when applying the Civil Law standard.

(vi) Consider insurance. Some claims may be insurable, especially where the risks are marginal. Insurers or underwriters will, of course, need reports from surveyors and in many cases expert counsel. Usually, insurance will only be offered on a postplanning basis.

(vii) Subject to the views of insurers or underwriters that are being contemplated, always use the neighbourly letter. Keep neighbours informed. It is better to use a 
direct approach without always necessarily mentioning rights of light, although this may be needed in some cases and will keep the neighbours on your side. Quite apart from the use of letters, models and invitations to presentations are often of importance in large developments. Keep a record of the addresses and the responses from those who are being informed. Such records may assist in defending injunction claims brought in at a later stage if it can be shown that neighbours and other parties have failed to assert rights in a timely manner. A serious delay in asserting a right to injunction is one of the principal defences to that type of claim.

(viii) If acting for the developer, make open offers of compensation. If acting for the objector, never make open offers of compensation, but if you must, always make them without prejudice. Never use the words 'subject to contract' when making compromise offers, as they have has no bearing in terms of the exclusion of offer from the eyes of the Court if the matter becomes litigated. Only communications made without prejudice are so privileged. In chains of emails ensure that the without prejudice privilege is applied to all the emails. This can often get overlooked.

(ix) Take planning objections seriously, particularly if based on rights of light on a legitimate footing. Consider with your rights of light surveyor how, if at all, those objections can be dealt with. Here, of course, one has to have regard not only to the planning (BRE standards), but also for the Civil Law standards mentioned above.

(x) Be prepared to modify plans. Once again, if steps to isolate rights of light issues are taken at a pre-planning stage, it is much easier to deal with them than afterwards.

(xi) Never forget that party wall awards, etc do not prevent rights of light claims; this is clear from section 9 of the Party Wall Etc Act 1996.

\section{TWO 'CASE STUDIES’}

The author has recently had experience of two contrasting matters where advice taken in one case at an early stage was determinative in avoiding any rights of light disputes and in the other case where advice was not taken at an early stage and where litigation resulted. The contrast is obvious. No doubt there are many such examples of each. The stress in this paper is really on the first type of case, where advice taken at an early stage can avoid the costs and perils of litigation.

\section{Case study 1}

This was a residential development of new flats in an outer London suburb. The area was sensitive, with high-value Edwardian houses all with rights of light. The developer's solicitor, planning adviser, architect and rights of light surveyor all worked together at the pre-planning stage to produce a scheme that recognised the need to reduce any substantial interference with the rights of light of at least two neighbours. Once that was done the developer's solicitor instructed the author to advise on whether the proposed development presented an acceptable risk in terms of potential litigation, bearing in mind the steps taken to design a building that did not cause a substantial interference with rights of light. Positive advice was given, planning consent was obtained and neighbourly letters were sent. The building went up without any litigation.

\section{Case study 2}

The author was asked to defend a claim for interference with light in a historic city in the North of England. The defendant had built right up against some windows that plainly had 
enjoyed light for many years. While party wall surveyors had been appointed and an award produced (under which the building was constructed), no one advising the defendant had focussed at an early stage on rights of light. They thought that the Party Wall Award would get rid of the problem and that the neighbour's non-assertion of rights of light at that stage was enough. When the building was built, the neighbour issued proceedings. There was no defence to the claim save as to the remedy where, because of the delay by the neighbour in enforcing his rights, damages might have been the likely outcome. To avoid defeat and costs, the client acquired the neighbour's building. If he could not have done so, the likely outcome was either an injunction to pull down the infringing building, or a very large award of damages, plus costs in excess of $£ 100,000$ for both parties.

\section{THE CONSEQUENCES OF GETTING IT WRONG}

It is obvious from the narrative of this paper that if you get it wrong and fail to consult experts at an early stage, isolate rights of light problems, identify them and seek to deal with them effectively, the consequence will be costly litigation and in the worst case an injunction, if not a heavy damages award against your client. In addition, as already mentioned above, there is a very heavy burden of costs. The main message in this paper is to take a long view and to see the danger signs that rights of light exist ahead, for if they are dealt with in a timely and effective manner, the proposed development can proceed smoothly.

(C) Andrew Francis

\section{Notes}

1 Light to gardens, etc is governed by the 'High Hedges' legislation in the Anti-Social Behaviour Act 2003, Part 8, and is not dealt with here, as quite different rules apply under that Act.

2 (2007) Ch 135.

3 (1904) AC 179.

4 See footnote 2 above.

5 (2007) EWHC (Ch) 212.

6 (1961) 13 P\&CR 77.

7 (2000) 82 P\&CR 286.

8 (1995) IEGLR 158. 